\title{
Strain-rate enhancement at Dye 3, Greenland
}

\author{
Timostur Thorsteinsson, ${ }^{1}$ E. D. Waddington, ${ }^{1}$ K. C. Taylor, ${ }^{2}$ R. B. Alley, ${ }^{3}$ D. D. Blankenship ${ }^{+}$ \\ 'Geophysics Program, University of Washington, Seattle, Washington 98195, L.S.A. \\ ${ }^{2}$ Desert Research Institule, Lnizersity and Community College System of Nevada, Reno, Nevada 89506, L.S.A. \\ "Earth System Science Center, The Pennsyliania State University, University Park, Pennsylvania 16802, U.S.A. \\ ${ }^{4}$ Institute of Geophysics, Unizersity of Texas, Austin, Texas 78759, U.S.A.
}

\begin{abstract}
Ice at depth in ice sheets can be softer in bed-parallel shear than Glen's flow law predicts. For example, at Dye 3, Greenland, enhancement factors of 34 are needed in order to explain the rate of borehole tilting. Previous authors have identified crystal fabric as the dominant contributor, but the role of impuritics and crystal size is still incompletely resolved. Here wc use two formulations of anisotropic flow laws for ice (Azuma's and Sachs' modcls) to account for the effects of anisotropy, and show that the measured anisotropy of the ice at Dye 3 cannot explain all the detailed variations in the measured strain rates. The jump in enhancement across the Holocene- Wisconsin boundary is larger than expected from the measured fabrics alone. Dust and soluble-ion concentration divided by crystal size corrclates well with the residual enhancement, indicating that most of the "excess deformation" may be due to impurities or crystal size. While the major features of the deformation at Dye 3 are explained by anisotropy and tempcrature, results also suggest that further research into the role of impuritics and crystal size is warranted.
\end{abstract}

\section{INTRODUCTION}

The deep ice core at Dye 3, Greenland, was drilled in the summers of 1979-81, reaching near bedrock at $2037 \mathrm{~m}$ depth. The liquid-filled borehole was surveyed in 1981 after the drilling, and twicc each ycar in 1983, 1985 and 1986 . Temperature, diameter and liquid pressure were measured in addition 10 inclination and azimuth (Gundestrup and Hansen, 1984; Dahl-Jenscn and Gundestrup, 1987). The surface temperature at Dye 3 is about $-20^{\circ} \mathrm{C}$, and the near-bedrock temperature is $-13^{\circ} \mathrm{C}$. The basal velocity is thus assumed to be zero. The surface velocity is found to be $12.5 \mathrm{~m} \mathrm{a}^{-1}$ by integrating the measured tilting rate in the borehole. This agrees with independent geodetic measurements of the surface velocity (Dahl-Jensen and (Eundestrup, 1987).

Iorizontal shear strain rate can be calculated from borehole inclination measurements. These measurements at Dye 3 have revealcd that the strain rate in the decp, Wisconsinan ice $(0-254 \mathrm{~m}$ above the bed $)$ is much higher than the rate expected for pure isotropic ice. This increased deformation rate is commonly describcd with an cnhancement factor, $E_{(i j)}=\dot{\varepsilon}_{i j} / \dot{\varepsilon}_{i j}^{G}$, which is the ratio of the measured strain rate over what Glen's (isotropic) flow law (Glen, 1958) would give. Figure 1, following Dahl-Jensen and Gundestrup (1987), shows that the cnhancement factor for Dye 3 reaches in places a value atpproaching 4 . Ice-flow calculations based on Glen's flow law thus cannot reproduce the strain rates measured in the Dye 3 borchole. We know that crystal fabric does play a major role in the deformation of ice (Steinemann, 1958; Russell-Head and Budd, 1979; Duval, 1981; Duval and Le Gac, 1982; Budd and Jacka, 1989; Van der Veen and Whillans, 1990; Alley, 1992; Azuma, 1994; Azuma and Goto-Azuma, 1996; Castelnau and others, 1996). A strongly anisotropic aggregate of ice is much softer in simple shear applied normal to the mean $c$-axis direction

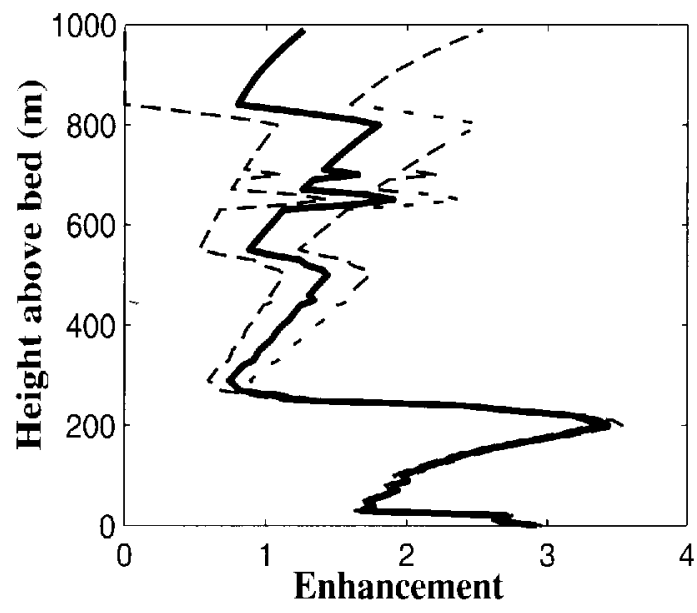

Fig. 1. Enhancement at Dye 3, using an $A_{0}$ value that is 1.7 times the reference value from Paterson (1994), following Dahl-Jensen and Gundestrup (1987). Errorestimates (dotted lines) are based on uncerlainlies reporled in borkhole lilling by Dahl-Fensen and Gundestrup (1987).

than is isotropic ice under the same stress condition. From thin-scction measurements and sonic logging (laylor, 1982; Herron and others, 1985) at Dye 3, we know that the ice there devclops an incrcasingly anisotropic fabric with depth

Mechanical tests on ice extracted from the Dye 3 borehole should provide insight into the expected in situ mechanical bchavior. Simple shcar and compression tests commonly yicld enhancement factors of 8 and 3 , respectively, for ice deforming in steady state (Budd and Jacka, 1989). Mechanical tests on the Dye 3 core Shoji and Langway, 1985,1988 ) have shown that in situ fabrics give enhancement factors as large as 17 in uniaxial compression at near $45^{\circ}$ to vertical, clearly indicating that a strong vertical $c$-axis fabric contributed to the enhancement factor. However, for a given 
sonic relocity, i.e. constant cone angle, the enhancement factor in their cxperiments varied by a factor of 2-5 (Shoji and Tangway, fig. 6), suggesting that a factor of $\sim 2$ in enhancement may fall within the expected uncertainty limits of the experiments. Possibly damage such as microcracking on basal planes due to decompression could accentuate the anisotropy. Due to difficulties of testing small samples at atmospheric pressure, we need to complement these mechanical test results with models of the in situ deformation.

Pimienta and others (1988) found no relation between impurities (soluble and insoluble), crystal size and enhancement in uniaxial and biaxial compression tests carried out on ice samples from the $2040 \mathrm{~m}$ Vostok ice core; they also concluded that anisotropic fabric explaincd all the Dye 3 deformation. However, other authors have suggested that impurities can soften icc (c.g. Dahl-Jensen and Gundestrup, 1987; Shoji and Langway, 1987; review by Paterson, 1991).

Our starting-point in examining the deformation at $\mathrm{D}_{\mathrm{ye}} 3$ is Glen's flow law Glen, 1958) which accounts for the stress and temperature dependence of ice-deformation rate. First, we explore the effects of fabrics on the flow properties of ice. We use a new model for anisotropic ice (Azuma, 1994; Azuma and Goto-Azuma, 1996), and also Sachs'model (Sachs, 1928) to account for the anisotropy. We then explore the effect of impurities on the mechanical properties of ice in order to further explain the deformation measured in the Dye 3 borchole.

\section{THE CONSTITUTIVE RELATION}

The two flow laws that we use both assume, in our formulation, that ice crystals deform only by slip in the basal plane and that the stress is homogeneous. The first assumption has been confirmed by experiments on ice; other slip systems are at least 60 times more difficult to activate (Duval and others, 1983). The second assumption ensures stress equilibrium, but not compatibility; that is, grains can deform in such a way as to form overlaps and/or voids. This is not considered a serious problem because diffusional processes including grain-boundary migration probably allow grains to recover without impeding the bulk deformation rate (Mcans and Jessel, 1986).

\subsection{General formulation of anisotropy}

When $\tau^{s}$ is the resolved shear stress on slip system $s$, then the rate of shearing, $\dot{\gamma}^{s}$, on that slip system is

$$
\frac{\dot{\gamma}^{s}}{\dot{\gamma}_{0}}=\left(\frac{\tau^{s}}{\tau_{0}^{s}}\right)^{n}
$$

where $\dot{\gamma}_{0}$ and $\tau_{0}^{s}$ are the reference resolved shear strain rate and shear stress, respectively, and $n$ is the stress exponent. Ice has only one easy slip system, the basal plane, so we can rewritc Equation (1) as

$$
\dot{\gamma}^{s}=\beta(T) \tau^{s^{\prime \prime}}
$$

where $\beta=\dot{\gamma}_{0} / \tau_{0}^{\prime \prime}$ is a function of temperature, $\beta(T)=\beta_{0} A(T)$ and $\beta_{0}$ will be chosen so that the strain rate for a random distribution of $c$ axes will match isotropic ice. The resolved shear stress $\tau^{s}$ is given by

$$
\tau^{s}=S_{i j}^{s} \sigma_{i j}=\tilde{S}^{s}: \tilde{\sigma}
$$

wherc $\sigma_{i j}$ is the deviatoric Cauchy stress tensor acting on the grain, and

$$
S_{i j}^{s}=b_{i}^{*} n_{j}
$$

is the Schmid tensor, which gives the transformation from the crystal coordinate system (microscopic) to the laboratory coordinate system (fixed, macroscopic), $\vec{n}$ is the slip-plane normal and $\vec{b}$ is the slip direction (Burgers vector). For ice, $\vec{n}$ is the crystallographic $c$ axis, so we write $\vec{n}=\vec{c}$.

The strain ratc is defined by $\dot{\varepsilon}_{i j}=\frac{1}{2}\left(L_{i j}+L_{j i}\right)$, where $L_{i j}=\partial v_{i} / \partial x_{j}, v_{i}$ are the velocity components and $x_{i}$ are the coordinates in a reference frame fixcd with respect to the laboratory (Molinary and others, 1987).

The strain rate in the macroscopic reference frame is related to the microscopic shcar strain rates by the relation

$$
\dot{\varepsilon}_{i j}=\sum_{s} R_{i j}^{s} \dot{\gamma}^{s}
$$

where $R_{i j}=\frac{1}{2}\left(S_{i j}+S_{j i}\right)$.

From Equations (2) and (5) we get (note that $R_{k l} \sigma_{k l}=$ $S_{k l} \sigma_{k l}$ if $\sigma_{i j}$ is symmetric)

$$
\dot{\varepsilon}_{i, j}=\beta(T) \sum_{s} R_{i, j}^{s}\left(R_{k l}^{s} \sigma_{k l}\right)^{n},
$$

which gives the strain rates of a single crystal in the macroscopic coordinate system.

\subsection{Sachs' model}

In Sachs' model (Sachs, 1928) the stress is assumed to bc homogeneous, so that the stress acting on cach grain is equal to the macroscopic stress acting on the aggregate. The stress tensor, $\sigma_{k l}$, in Equation (6) is thus just the stress applicd to the bulk. The macroscopic strain rate of the bulk is then just the arithmetic average of the strain rates of the individual grains, given by

$$
\dot{\varepsilon}_{i j}^{s}=\frac{1}{N} \sum_{g \cdots 1}^{N} \dot{\varepsilon}_{i j}^{g},
$$

where $\dot{\varepsilon}^{g}$, the strain rate of an individual grain, is given by Equation (6), and $N$ is the total number of grains.

The value of $\beta_{0}$, chosen to make isotropic ice behave according to Glen's flow law, is $\beta_{0}=9$.

\subsection{Azuma's model}

For bulk deformation, Azuma (1994) takes the mean value of the Schmid tensor for individual grains,

$$
\bar{S}_{i j}=\frac{1}{N} \sum_{g=1}^{N} S_{i j}^{q},
$$

where $S$ is calculated assuming that $\vec{b}=\vec{m}$, where $\vec{m}$ is the direction of the projection of the traction, $\vec{T}$, on the hasal plane. This is possible bccausc the basal planc is nearly isotropic for $2<n<4$ (Kamb, 1961). The traction is given by

$$
T_{i}=\sigma_{i j} c_{j},
$$

and its direction, $\vec{m}$, by

$$
\vec{m}=\frac{\vec{c} \times(\vec{T} \times \vec{c})}{|\vec{c} \times(\vec{T} \times \vec{c})|} .
$$

Consequently, for ice we can write the Schmid tensor as $S_{i j}=m_{i} c_{j}$.

The macroscopic strain rate is then given by

$$
\dot{\varepsilon}_{i j}^{A}=\beta(T) \bar{R}_{i j}\left(\bar{R}_{k l i} \sigma_{k i l}\right)^{n} .
$$

This model effectively replaces each crystal with a crystal having the mcan orientation, given by the average value of $S$. 
The value of $\beta$ is chosen to make the Azuma model reproduce Glen's flow law in the case of isotropic ice, i.e. random $c$-axis fabric. This value is $\beta_{0}=18$, which is twice the value found for Sachs' model.

\subsection{Comparison of the two models}

The degree of anisotropy is described as a cone angle, which is the apex angle of a cone within which all the $c$ axes are uniformly distributed. Isotropic ice has a cone angle of $90^{\circ}$; anisotropic icc has smaller cone angles. The conc can be parallel or oblique to the direction of gravity. For Dye 3, the vertical symmetry of thin-section fabrics and orthogonal components of the sonic velocities on the ice core (Herron and others, 1985) strongly suggest that the cone axis is vertical. The same assumptions apply to the interpretation of the borcholc sonic velocities (Taylor, 1982).

In simplc shcar, strongly anisotropic ice can deform as much as nine times faster than isotropic ice, according to Azuma's model, and 4.5 times faster according to Sachs' model (Fig. 2). In uniaxial compression along the cone axis of progressively more anisotropic samples, the ice gets softer by as much as a factor of 3 between cone angles of $90^{\circ}$ and $60^{\circ}$, because these fabrics contain progressively fewer hard grains oriented near $90^{\circ}$. Samples with cone angles smaller than $60^{\circ}$ bccome progressively stiffer with decreasing cone angle (Fig. 2) because there is less resolved shear stress on the basal planes.

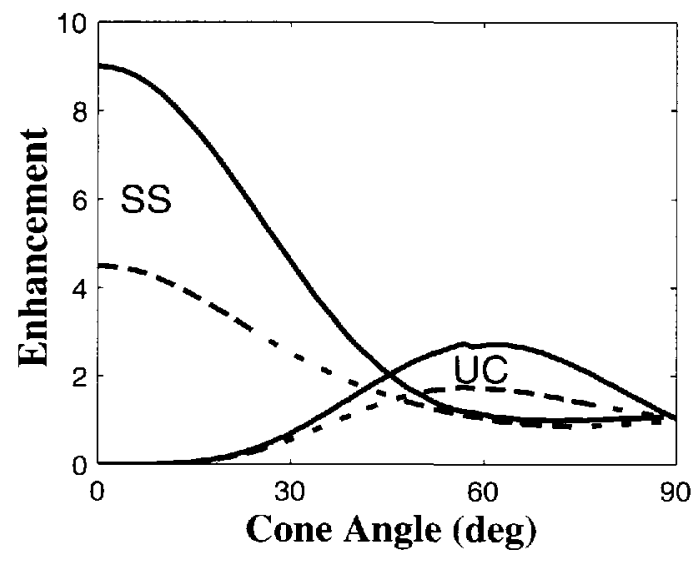

Fig. 2. Enhancement in simple shear (SS) and uniaxial compression (UC) calculated from Sachs' (dashed lines) and Azuma's (full lines) models.

Note that Sachs' and Azuma's model are identical in the casc of a single crystal; it is only through the choice of $\beta_{0}$ for isotropic ice that we obtain the different strain rates for cone angle of $0^{\circ}$, i.e. single crystal.

\section{DATA SOURCES}

We use Dye 3 borehole tilt measurements for strain rates (Dahl-Jensen and Gundestrup, 1987, fig. 2). The measurcments were made every $2.5-5 \mathrm{~m}$ from near the bedrock up to $330 \mathrm{~m}$. From there to the surface they were made at $25 \mathrm{~m}$ intervals. In measurements above $1200 \mathrm{~m}$ the standard deviations on $\partial u / \partial z$ are of the same order of magnitude as the parameters themselves (Dahl-Jenscn and Gundestrup, 1987). Almost all the deformation takes place in the lowermost $1000 \mathrm{~m}$, so all our calculations are donc therc.
We use the stress-state values given by Dahl-Jensen (1985), who calculated the stresses and made corrections due to the local topography.

The temperature profile (Gundestrup and Hansen, 1984) shows that most of the change in temperature happens in the lowermost $400 \mathrm{~m}$. This rcsults in an enhancement (through the temperature dependence of the flow laws) of a factor of 2 between $400 \mathrm{~m}$ and the bed. 'The data used for strain rate, stress and temperature are shown in Figure 3.

Fabric data were obtained in two ways. Herron and others (1985) measured fabrics in thin sections (Fig. 4). The thin-section measurements are based on observations of $N \approx$ several hundred crystal axes at sclected depths. The fabric is expressed by Herron and others (1985) in several ways, including (1) the apex angle of a cone containing $90 \%$ of the crystal $c$ axcs, and (2) the normalized length $R / N$ of the resultant vector $\vec{R}$ obtained by summing all $N$ $c$-axis vectors. Thin-section measurements of fabric were made on the core at $50-100 \mathrm{~m}$ intervals.
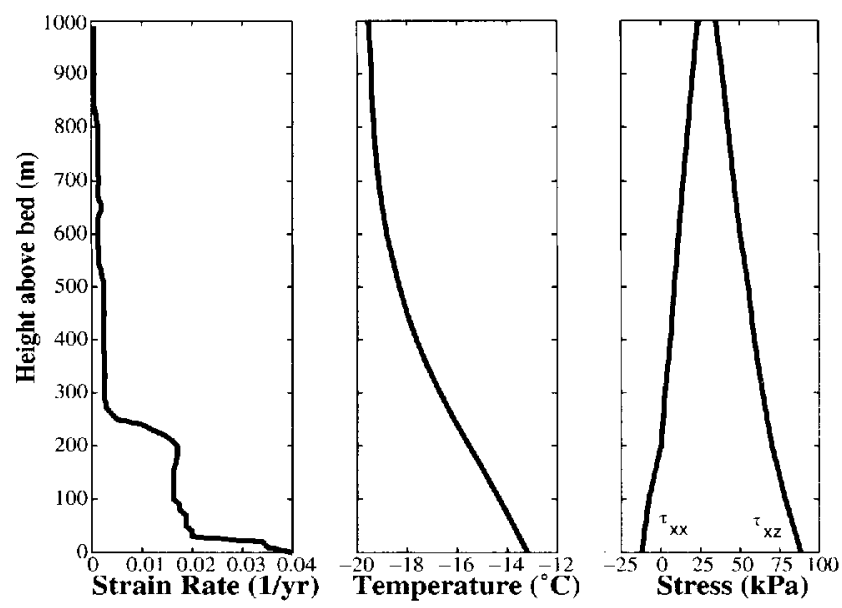

Fïg. 3. Measured horizontal strain rates and temperature, and the calculated stress at Dye 3.

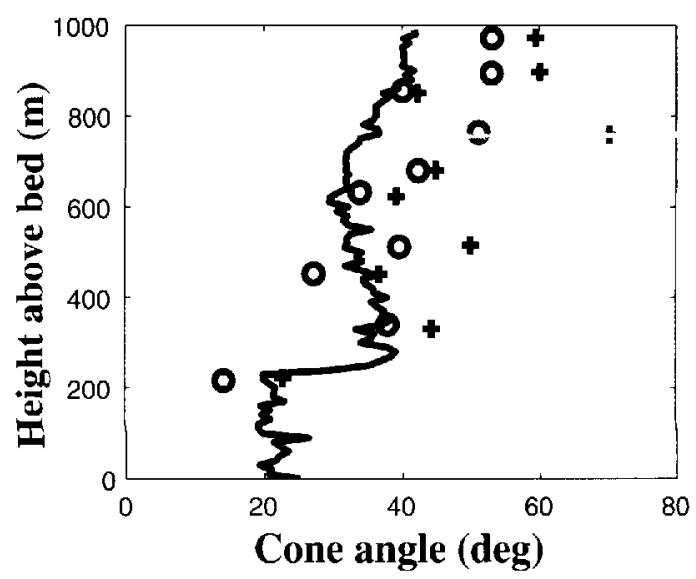

Fig. 4. Measured cone angles. Solid line is cone angle calculated from compressional wave-velocity measurements (Taylor, 1982). Crosses are cone angles enclosing $90 \%$ of the $c$ axes from the thin-section data, and circles are cone angles with uniformly distributed c axes giving the same $R / \mathcal{N}$ slatistics as the measured thin sections (Herron and others, 1985).

Fabric data were also obtained from borehole sonic-logging measurcments (Taylor, 1982) using vertically traveling compressional waves. The velocity measurements were made through $7 \mathrm{~m}$ of ice, which is the spacing between the source and receiver. Velocities were calculated at $3.33 \mathrm{~m}$ in- 
tervals. Inclination data for the borchole were used to correct for variations in propagation angle. Wave velocities can be used to interpret fabric in terms of the cone (apex) angle because ice is elastically anisotropic, and the elastic anisotropy has the same symmetry as the plastic anisotropy. Bennett (1968) derived the relationship between ice fabrics and wave velocities that was used to calculate the cone angle from the compressional wave velocity. We use the samc model of uniformly distributed crystal axis within a cone when interpreting the compression wave velocitics and calculating the mechanical properties of the ice.

The difference between the inferred cone angles from the sonic $\log$ and the $90 \%$ cones from thin sections (Fig. 4) is mainly due to the non-uniform distributions of $c$ axes within the $90 \%$ cones from the thin sections, as was pointed out by Herron and others (1985); the $90 \%$ cone angle is a relativcly poor statistic for representing the avcragc oricntalion of crystals in a thin section. For example, if $80 \%$ of the $c$ axes cluster tightly near the vertical, while the others have high inclinations, then the $90 \%$ conc angle must be large enough to enclose half of the outliers. Yet the deformation rate of this sample could be very different from that of a sample with uniformly distributed $c$ axes spanning the $90 \%$ cone, and the tight central cluster alone might better characterize the deformation rate of the sample. $R / N$ is a better statistic than the $90 \%$ contour cone angle for expressing the fabric distribution, bccausc cvery $c$ axis in a thin section, not just those near the $90 \%$ contour line, contributes to $R / N$. In order to compare the sonic-vclocity cone angles and the thin-section data, we use the cone angles for uniformly distributed $c$ axes that would have the same $R / N$ statistic as cach mcasured thin section. These cquivalent cone angles, shown by open circles in Figure 4, are clearly a better match to the sonic-log cone angles. It is also important to remember the very different scales that these two methods measure. The sonic log gives an avcrage conc angle through $7 \mathrm{~m}$ of ice, while the thin sections are only about $0.5 \mathrm{~mm}$ thick. I'his may account for the higher variability of the cone angles from the thin sections. There are also a number of complexities that arise in thin-section measurements. Coarse grains can bias the measurements by passing through the plane of the thin section in many places. Polygonization can give the sense of small crystal size, but the $c$ axcs, duc to the subdivision process, are very similar for the new grains (Alley and others, 1995). Hence, groupings and other features of the $c$ axes are likcly (Herron and others, 1985; Alley and others, 1997) that reveal a huge amount about active processes but may not average over a large enough volume to capture the fabric controlling the deformation. We note that the thin sections are very important as a tool to infer the symmetry and distribution of $c$ axes, and also of course if one is modeling ice on cm scales.

\section{CALGULATIONS}

We perform two sets of calculations. First, we calculate the strain rate, using information on stress, temperature and fabric. Sccond, we calculate the fabric, using information on stress, temperature and measured strain rates.

We use $\sim 1000$ c axes for each point of calculation, which are at $10 \mathrm{~m}$ intervals from the bed to $1000 \mathrm{~m}$ height (recall that Dahl-Jensen and Gundestrup (1987) found virtually no deformation above $1000 \mathrm{~m}$ ).
For the calculations, we used $n=3$ (Budd and Jacka, 1989 and the Arrhenius relation $A(T)=A_{0} \exp (-Q / R T)$ for the temperature dependence, where $Q=60 \mathrm{~kJ} \mathrm{~mol}{ }^{1}$ (Paterson, 1994, p. 96) and $R=8.314 \mathrm{~J} \mathrm{~mol}^{1} \mathrm{~K}$ '. Using $A\left(-20^{\circ} \mathrm{C}\right)=$ $1.7 \times 10^{-16} \mathrm{kPa}^{-3} \mathrm{~s}^{-1}$ (Paterson, 1994) as a reference value, we find $A_{0}=4.15 \times 10^{4} \mathrm{kPa}^{3} \mathrm{~s}$, using the values for $Q$ and $R$ defined above.

We view the value of $A_{1 /}$ as an adjustable parameter; values reported vary by factors of $\sim 2$ (Paterson, 1994, table 5.1). In our calculations we therefore use $\mathcal{A}_{0}=f_{C}^{\mathrm{X}} A_{0}$, where $f$ is a factor chosen using two different critcria (C) for given flow law $\mathrm{X}(\mathrm{X}=\mathrm{S}$, A or G refers to Sachs' model, Azuma's model or isotropic (Glen's) flow law, respectively). First, we choose $f$ such that the strain rates that we calculate in the Holocene ice match the measured strain rates as closely as possible with each flow law; we call these scalars $f_{\mathrm{II}}^{\mathrm{X}}$. For our second approach, we ensure that the strain rate in the Wisconsin ice is never over-predicted after we account for the anisotropy. This is equivalent to saying that the impurities can only have a softening effect on the ice; we call these scalars $f_{\mathrm{W}}^{\mathrm{X}}$.

To characterize the effects, in addition to fabric, that might be necessary to explain the measurcd borchole tilting we define $k$ through

$$
\dot{\varepsilon}^{\mathrm{m}}=\dot{\varepsilon}^{\mathrm{X}}(1+k)
$$

where $\mathrm{m}$ refers to measured values and $\mathrm{X}$ refers to the flowlaw description used. $k$ is thus a measure of how much excess deformation remains at each depth after we have accounted for the anisotropy. $k$ should thus be 0 if the flow law $\mathrm{X}$ could explain all the strain rate measured.

\section{RESULTS}

Figures 5 and 6 show the calculated strain rates and excess dcformation, $\mathrm{k}$, using the two criteria $f_{\mathrm{H}}^{\mathrm{X}}$ and $f_{\mathrm{W}}^{\mathrm{X}}$, respectively. The values of $f_{C}^{X}$ 's are found in Table l. We note that both anisotropic models capture some of the major features of the measured profile. However, neither of them can cxplain all the variations.

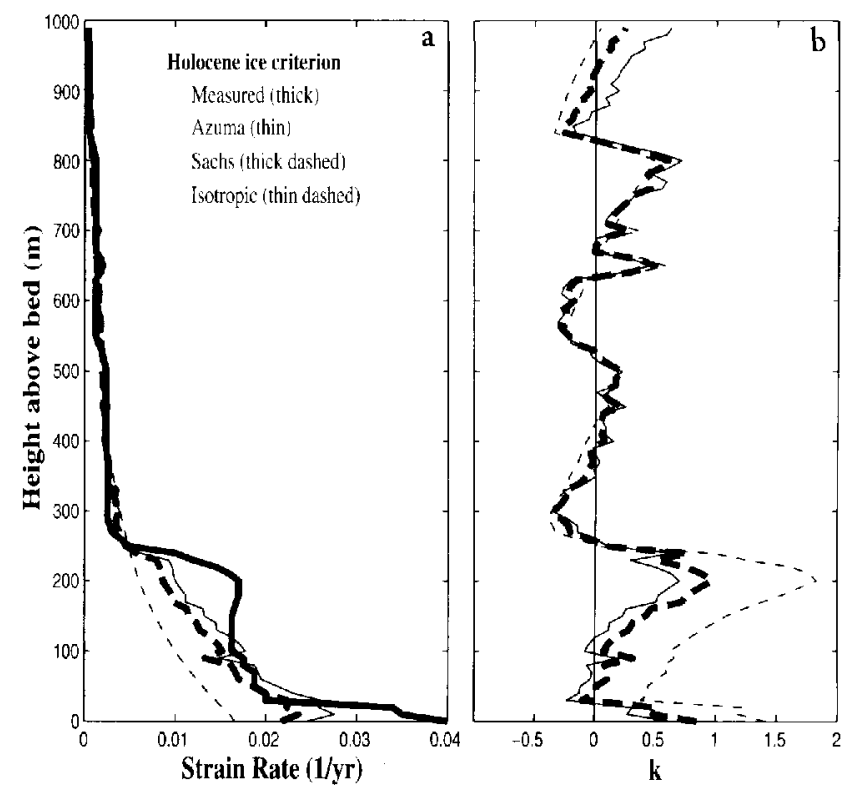

Fig. 5. (a) Measured (solid line) and calculated horizontal strain rates, using the Holocene-ice criterion. (b) The corresponding $k$ values for Azuma (thin solid line), Sachs (thick dashed line) and isotropic (thin dashed line) ice. 

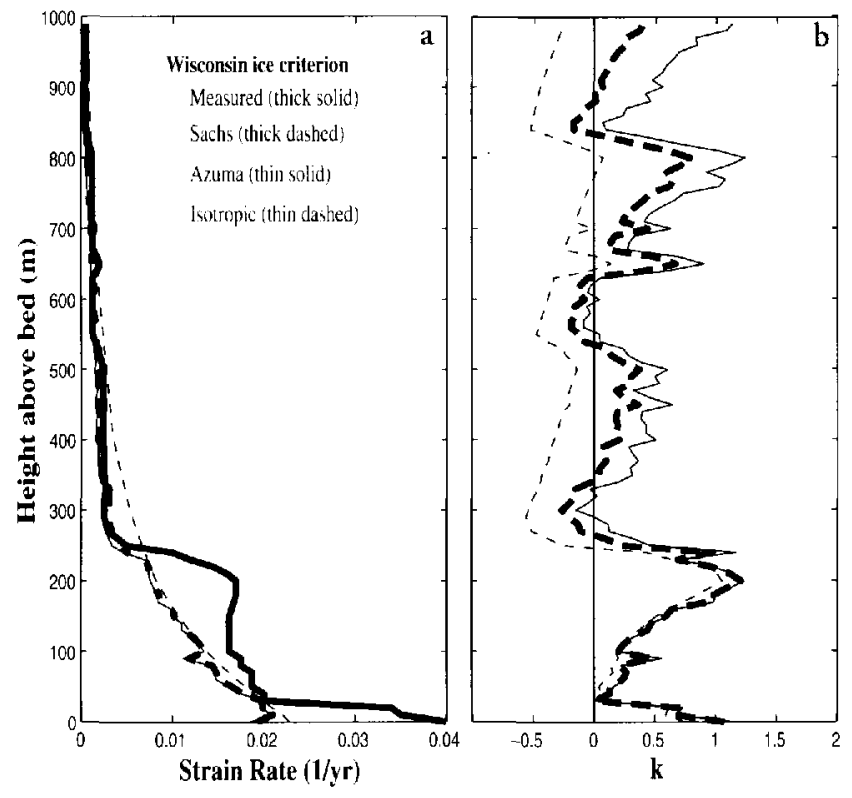

Fig. 6. (a) Measured (solid line) and calculated horizontal strain rates, using the Wisconsin-ice criterion. (b) The corresponding k values for Azuma (thin solid line), Sachs (thick dashed line) and isotropic (thin dashed line) ice.

Table 1. The value of $f_{\mathrm{C}}^{\mathrm{X}}$ for the different criteria and flow lazes used

\begin{tabular}{lccc}
\hline & Sachs & Azuma & Isotropic \\
\hline Holorene & $f_{\mathrm{H}}^{\mathrm{S}}=0.91$ & $f_{\mathrm{H}}^{A}=0.54$ & $f_{\mathrm{H}}^{\mathrm{G}}=2.06$ \\
Wisconsin & $f_{\mathrm{W}}^{\mathrm{S}}=0.81$ & $f_{\mathrm{W}}^{\mathrm{A}}=0.11$ & $f_{\mathrm{W}}^{\mathrm{C}}=2.84$ \\
\hline
\end{tabular}

In particular, note the large strain rate just below the Holocene-Wisconsin boundary, located $254 \mathrm{~m}$ above the bottom of the borehole. Deformation rate increases by a factor of 4 over a short depth interval. However, temperature and stress vary smoothly across the boundary, and the fabric, while it changes at the boundary, still cannot account for the factor of 4 with either of the anisotropic flow models that we use. Perhaps other anisotropic flow models might be able to account for this factor of 4 , although we are not aware of any that do. Another possibility is that the stiff (more strongly anisotropic) Wisconsin ice acts as a stress guide, therefore raising the longitudinal stress $\sigma_{x x}^{\prime}$. A simple calculation shows that in order to have the same strain ratc $\dot{\varepsilon}_{x x}$ for a layer with a $20^{\circ}$ cone as for a layer with a $40^{\circ}$ cone, one needs to increasc $\sigma_{x x}^{\prime}$ by a factor of 2. Increasing $\sigma_{x x}^{\prime}$ by a factor of 2 at Dye 3 has a very small effect on $\dot{\varepsilon}_{x z}$. Even in the extreme case where the longitudinal stress was zero before, and is now one-half of the shear stress, the increase in shear strain rate for a cone angle of $20^{\circ}$ is only about $10 \%$. So large crrors in the longitudinal stress, as long as they are smaller than about half the shear stress, will not change the shear strain rate by much.

We also note that at $100-200 \mathrm{~m}$ the measured strain rates arc constant or even slightly decreasing with increasing depth, while stress and temperature, i.e. factors that should increase deformation rate in any flow model, increase with increasing depth. The degree of anisotropy is constant, or even slightly increasing over the same depth interval, and thus either should not affect or else should also increase the deformation rate. From this observation, we must conclude that some factor in addition to fabric anisotropy is required to explain the observed deformation rate, regardless of how the response to fabric is modelled.

The mechanical tests of Shoji and Langway (1985, 1988) strengthen this conclusion, for they show a monotonic relation between cnhancement and sonic velocitics.

Figure 7 shows the cone angles, calculated using Azuma's and Sachs' models, required to explain all the mcasurcd strain rates solely with fabric variations, using the $f_{\mathrm{H}}^{\mathrm{X}}$ 's that we obtained for the Holocene ice. Common to both profiles is the fact that in order to explain the jump in strain rate below the Holocene-Wisconsin boundary, very strong anisotropy is necessary in the Wisconsin icc. In fact, a single crystal fabric would not be enough, but we terminated our calculations at $2^{\circ}$ cone angles. The cone-angle profile that we derive using the Wisconsin-ice criterion has essentially the same features as seen in Figure 7 and leads to the same conclusions. The sonic vclocity data do not support such strong anisotropy in this region.

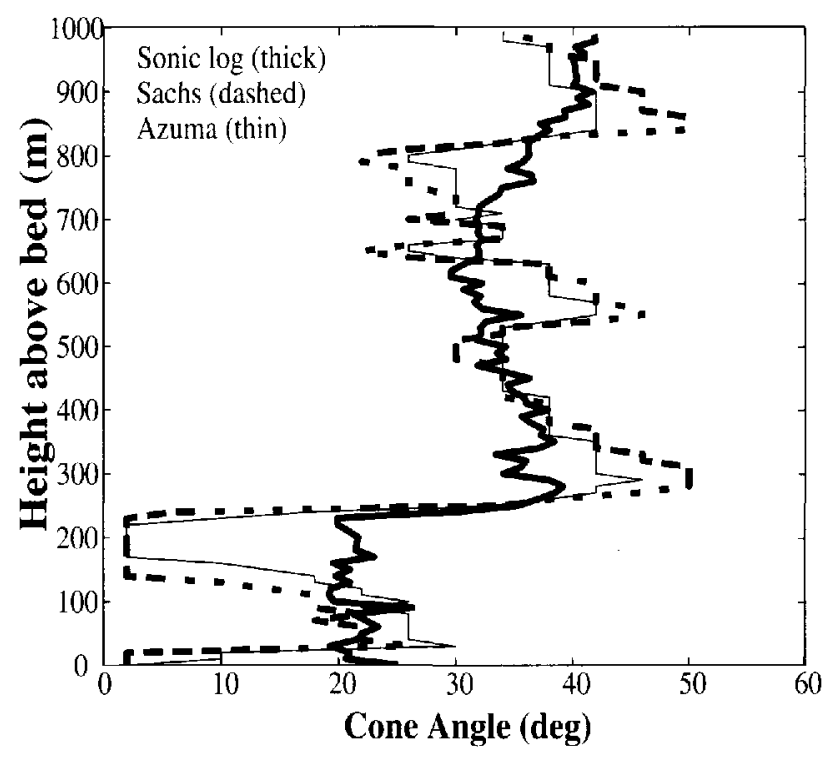

Fig. 7. Bold line shows cone angles obtained from the compressional wave-velocity measurements (sonic $\log$ ). Other two curves show cone angles required by the two anisotropic models (Sachs and Azuma), to produce the best match to the measured strain rates for the given temperature and stress. Here we use the $f_{\mathrm{H}}^{\mathrm{X}}$ value determined from the Holocene-ice criterion.

\section{INCLUDING IMPURITIES}

So far we have "accounted" for the effects of stress, temperature and fabric. But excess deformation, $k$, remains unexplained. Now we cxamine the role of other possible factors, individually or combined, which we will call "Y", that may influence the rheology of ice. We consider impurities, dust and dissolved-ion concentrations, and crystal size. We rewrite Fquation (12) as

$$
\dot{\varepsilon}^{\mathrm{m}}=\dot{\varepsilon}^{\mathrm{x}}\left(1+k_{\mathrm{Y}}+k^{*}\right)
$$

where $k_{\mathrm{Y}}$ is the deformation correlated with the dust or ion concentration, crystal size or some combination of these. $k^{*}$ will be (we hope) a random residual. In other words, we have assumcd that the excess deformation is duc to some "Y" plus an error term, $k=k_{\mathrm{Y}}+k^{*}$.

We assume that $k_{Y}=(Y / a)^{p}$, where $Y$ can be concentration, crystal size or some combination of these, and a 
and $p$ are constants to be determined by the data. We then find $a$ and $p$ that minimize $N \tilde{\sigma}^{2}=\sum_{j=1}^{N}\left(k^{j}-k_{\mathrm{Y}}^{j}\right)^{2}$, where $N$ is the number of data points. The correlation between $k$ and $k_{\mathrm{Y}}$ is then given as $\rho=\operatorname{cov}\left(k, k_{\mathrm{Y}}\right) /\left(\sigma_{k} \sigma_{k \mathrm{~V}}\right)$ (Barlow, 1989, p. 16). The best correlation and smallest $\tilde{\sigma}$ were found for dust and for ion concentration divided by crystal size.

The dust concentration at Dye 3 (Hammer and others, 1985) correlates well with the dissolved ions $(\rho=0.829)$ and the inverse crystal size. We get the smallest $\tilde{\sigma}^{2}$ when comparing $k$ and the dust concentration, by using a linear relationship $k_{\mathrm{d}}=a C(z)$, where $C$ is the concentration in $\mathrm{mg} / \mathrm{kg}$ averaged over $\sim 5 \mathrm{~m}$ depth to replicate the smoothness of the sonic $\log$ by the $7 \mathrm{~m}$ tool. The calculations are done 30$250 \mathrm{~m}$ above the bed, and therefore avoid the silty ice layer in the lowcrmost $23 \mathrm{~m}$. Figure 8 shows that the dust concentration is highly correlated to the excess deformation, $k$. The valuc of $a$ is $0.35-0.77$ for the two flow-law formulations and $\mathcal{A}_{0}$ selection criteria we used. The correlation coefficient $\rho_{\mathrm{d}}$ for Azuma's model is 0.83 and for Sachs' model 0.88 .
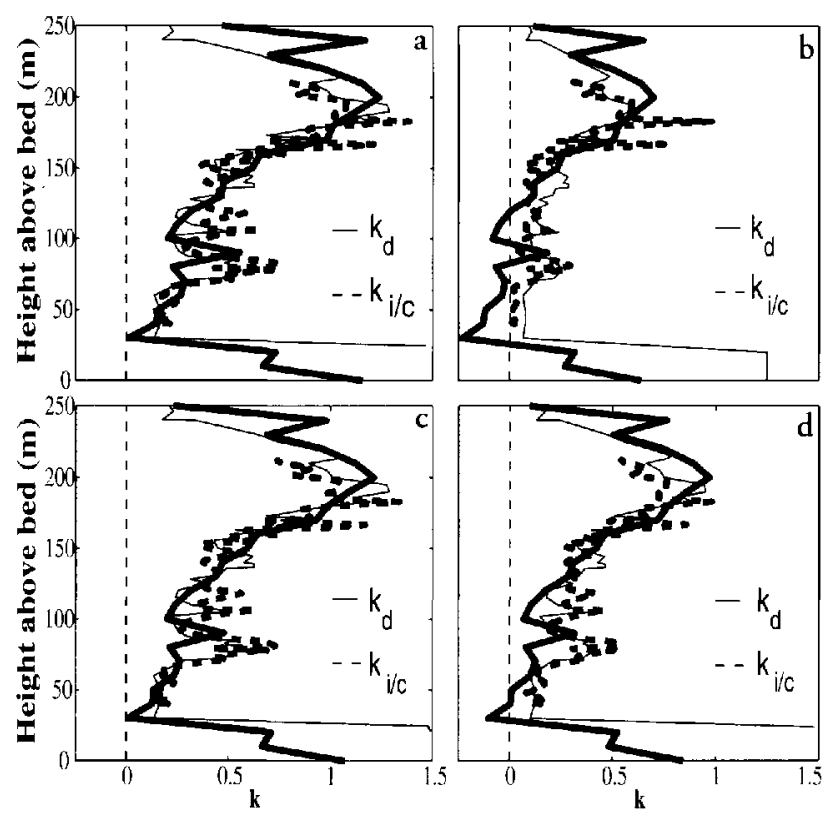

Fig. 8. Relating the dust concentration $\left(C_{\mathrm{d}}\right.$ ), using a linear function $k_{\mathrm{d}}=C_{\mathrm{d}} / a$ (thin line), and the ion concentration $\left(C_{\mathrm{i}}\right)$ divided by crystal size $(D)$, using a function $\left.k_{i / c}=\left[C_{\mathrm{i}} / a D\right)\right]^{p}$ (thick dashed line), to the excess enhancement $k=k_{\mathrm{Y}}+k^{*}$ (thick line) calculated with the tre oflow laws and criteria described in text. The zalues of $a$ and $p$ are given in Table 2. (a) Azuma's model using the Wisconsin-ice (WI) criterion; (b) Azuma using the Holocene-ice (HI) criterion; (c) Sachs' model using WI; and (d) Sachs' model using $H I$.

We do the same calculations for soluble ions divided by crystal size, as suggested by Cuffey and others (1996), using the sum of $\mathrm{Cl}^{-}, \mathrm{SO}_{4}{ }^{2-}$ and $\mathrm{NO}_{3}{ }^{-}$concentrations (DahlJensen and Gundestrup, 1987). For the relation $k_{i / c}=$ $\left[C_{\mathrm{i}} /(a D)\right]^{p}$, where $C_{\mathrm{i}}$ is the concentration $(\mathrm{mg} / \mathrm{kg})$ and $D$ is the crystal size ( $\mathrm{mm})$, wc find $p=1$ or 2 , and $a=286-404$. The values of $p$ and $a$ for each case are shown in Figure 8, which also shows that the correlation is good with $k$. The correlation coefficients are 0.84 (Holocene ice) and 0.86 (Wisconsin ice) for Azuma's model and 0.86 for Sachs' model.

The values of $\tilde{\sigma}^{2}$ and $\rho$ for both the criteria, the two flow models used and both $k_{Y}$ 's are summarized in Table 2 .

A correlation between residual enhancement and dust
Table 2. The parameters $a$ and $p$, and the statistics for the correlation of the excess enhancement, $k$, with dust, $k_{\mathrm{d}}=\left(C_{\mathrm{d}} / a\right)^{p}$, and ion concentration divided by crystal size, $k_{i / c}=\left[C_{\mathrm{i}} /(a D)\right]^{p}$

\begin{tabular}{|c|c|c|c|c|c|c|c|c|}
\hline & $k_{\mathrm{d}}$ & & $k_{\mathrm{d}}$ & & $k_{i j c}$ & & $k_{i_{j}, u^{\prime}}$ & \\
\hline & $a$ & $p$ & $\rho$ & $10^{-2} \tilde{\sigma}^{2}$ & $a$ & $p$ & $\rho$ & $10^{-2} \tilde{\sigma}^{2}$ \\
\hline Sachs, HI & 1.75 & 1 & 0.88 & 1.31 & 404 & 1 & 0.86 & 2.99 \\
\hline Sachs, WI & 1.30 & l & 0.88 & 1.44 & 296 & 1 & 0.86 & 3.25 \\
\hline Azumia, HI & 2.86 & 1 & 0.83 & 1.89 & 400 & 2 & 0.84 & 2.29 \\
\hline Azuma, WI & 130 & 1 & 0.83 & 1.56 & 286 & 1 & 0.86 & 3.40 \\
\hline
\end{tabular}

Notes: HI, Holocene icc; WI, Wisconsin ice.

does not necessarily mean that dust softens the ice. As noted above, dust also correlates strongly with the dissolved ions and the inverse crystal size, and since thesc are all so closely correlated it is difficult to say which one is responsible for the deformation. Ice containing small crystals often has strong anisotropy (Patcrson, 1991); our direct usc of the measured anisotropy already incorporates this effect. We cannot distinguish whether the insoluble dust or the dissolved ions make the ice softer, since they correlate so well; we argue that dissolved ions are more likely, although some of the arguments apply to dust as well.

At concentrations observed in the Dye 3 core and most other icc-shect ice, laboratory experiments and simple theory generally lead one to expect that increased impurity concentration will increase deformation rates (sec review in Paterson, 1994, p. 88-89). Solid impurities (e.g. silt, volcanic ash) at high concentrations in cold ice may decrease strain rates in laboratory cxpcriments (e.g. Hooke and others, 1972), but have little effect at low concentrations characteristic of non-basal icc-shect ice. Some field data sccm to indicate a softening effect of solid impurities (Swinzow, 1962), especially at high tempcraturc Echelmeyer and Zhongxiang; 1987), although it is always difficult to determine mechanisms in such field settings. Budd and Jacka (1989) concluded from a review of the ficld that solid impurities have little effect on creep deformation at ice-sheet concentrations and sub-freezing temperatures.

Experiments with soluble impurities (Jones and Glen, 1969; Nakamura and Jones, 1970, 1973; Paterson, 1991) indicate that their presence typically increases deformation of ice, although effects may be sensitive to the temperature, concentration and naturc of the impurity. As onc cxample, in constant-strain-rate tests in tension on single crystals of ice, introduction of $1.3 \mathrm{ppm} \mathrm{HCl}$ reduced the peak stress by about a factor of 2 (Nakamura and Jones, 1973).

Several mechanisms may be active (e.g. Nakamura and Jones, 1973; Weertman, 1973; Percz and others, 1980; Paterson, 1994). Motion of dislocations through the ice lattice may create mismatches at bonds (Bjerrum defects) that must be removed by diffusional processes to allow continued motion. Soluble impurities that substitute in the ice lattice create defects that specd this diffusional relaxation. Impurities may also create liquid zones or thicker disordered zones along dislocation cores and at grain boundaries that speed diffusional processes and cause or allow faster deformation.

Impurity concentrations can affect grain-sizes (e.g. Alley and Woods, 1996), and at least some models allow a grain-size effect on ice-deformation rates. However, as reviewed by Budd and Jacka (1989) (cf. Duval and Lc Gac, 
1980), grain-size does not seem to affect deformation rates significantly within the range of ice-shect conditions, and often is more of a response to deformation than a control on deformation.

Thus, a likely explanation is that solublc impurities specd diffusional processes and thus increase ice-deformation rates by introducing point defects, and pcrhaps also by incrcasing the volume of disordered or liquid material through which diffusion is enhanced. The smaller crystal size at high soluble-impurity levels would greatly facilitate this process. Whatever the mechanism, the literature suggests that the impurity-loading in the Wisconsin ice at Dye 3 is likely to cause some softening, as deduced by Paterson (1991).

\section{DISCUSSION}

By using anisotropic flow models, we can explain a large fraction of the total deformation. While we agree with Azuma and Goto-Azuma (1996) that the anisotropy explains most of the strain rate, there are still some important differences, especially in the Wisconsin ice. In general, we cannot tell from this study whether Azuma's flow law or Sachs' model is better for predicting the behavior of this ice.

Our approach in Equations (12) and (13) is to incorporate additional physical processes into the deformation model until the "unexplained deformation rate" $k$ approaches zero. If stress, temperature and anisotropy werc to explain all the measured deformation, then $k$ in Equation (12) would be zero. Our Wisconsin-icc critcrion for sclecting $\mathcal{A}_{1}$ assumes that addition of impurities can only soften the ice, at least for the concentrations observed at Dyc 3. This leads to values of $k$ in the Wisconsin ice that are mostly $<1$. The Holocene-ice criterion does result in a few negative values of $k$ in the Wisconsin ice, i.c. the ice should be stiffer than the model predicts (lower $\mathcal{A}_{0}$ value) rather than softer, but those negative $k$ values are very small, and the absolute value of $k$ is always $<1$. Most of the variation in $k$ seen in the Holocene icc in both cases can bc attributed to uncertainties in the measured strain rates.

Mcasurements on the ice core show that the impurity content changes rapidly right at the Holoccne-Wisconsin boundary. Within the Wisconsin ice there are large variations in impurity concentration which are correlated with the $k$ value, the excess enhancement after accounting for fabric.

Sonic logging is a very important method of obtaining information about the fabric in borcholes. Sonic logs that average over distances shorter than $7 \mathrm{~m}$ would be helpful, particularly in regions of rapid changes such as the Holocene- Wisconsin boundary and close to the bed. Thin-section measurements arc very time-consuming, but necessary in order to be able to draw conclusions about the c-axis distribution: are the $c$ axes within a cone, is the cone vertical and are the $c$ axcs uniformly distributed within it, or docs the ice have a multiple maximum fabric? Finally we point out that if we know that the $c$-axes distribution can be characterized by some distribution other than a uniform vertical cone (tilted cone, girdle, etc.), the sonic velocities for that distribution can be calculated and used to infer parameters of that distribution in the ice sheet.

\section{CONGLUSIONS}

'I'he enhancement at Dyc 3 (Fig. 1) has previously been at- tributed to various combinations of properties including fabric anisotropy, impurities and crystal sizc. By accounting for anisotropy, we can explain $\sim 75 \%$ of the peak enhancement at Dye 3. 'The strong correlation between the cxcess deformation and dust concentration or ion concentration divided by crystal size suggests that most of the excess deformation after accounting for fabric anisotropy can bc attributed to the impurities.

We can thus write a flow law for the instantancous deformation rate as

$$
\dot{\varepsilon}_{i j}=\beta_{0} A(T)[1+f(C, T)] R_{i j} \tau^{n},
$$

where $\beta_{0}$ is a constant, $A(T)=A_{0} \exp (-Q / R T), f(C, T)$ is a function of crystal size and/or impurity concentration whose importance may vary with temperature, $R_{i j}$ is the symmetric part of the Schmid tensor (Fquation (4) and $\tau$ is the resolved shear stress (Equation (3). More work is needed to clarify the form of $f(C, T)$. Our simple lincar temperature-independent form $f(C, T)=C(z) / a$ worked well for the dust concentration and the limited range of temperatures at Dye 3; however, it does not adequately reproduce the deformation of the silty bottom $23 \mathrm{~m}$, nor does it have a strong theoretical basis. For the ion concentration divided by crystal size a similar rclation also worked well. We feel duly cautioned by the epigraph to Paterson (1991), "Impurities like patriotism - are sometimes the last refuge of scoundrels (Bohren, 1983)". However, now that the effects of both temperature and fabric anisotropy can be incorporated in iceflow models, we conclude that impurities clearly emerge as the largest remaining factor influencing ice deformation at Dye 3 . This conclusion may also apply elsewhere.

\section{ACKNOWLEDGEMENTS}

We wish to thank S. Paterson for valuable comments on the manuscript, C. Bentley for help with the sonic logging, D. Dahl-Jensen for the temperature profile and K. M. Cuffey for illuminating discussions. This work was supported by grant OPP-9123660 from the U.S. National Science Foundation.

\section{REFERENCES}

Alley, R. B. 1992. Flow-law hypotheses for ice-shect modeling. . f. Glaciol, $38,129,245-256$.

Nlley, R. B. and C. A. Woods. 1996. Impurity influence on normal grain growth in the GISP2 ice core, Greenland. F. Glaciol., 42(141), 255260.

Alley, R. B., A.J. Gow and D.A. Meese. 1995. Mapping c-axis fabrics to study physical processes in ice. 7. Glaciol., 41 (137), 197-203.

Allc, R. B., A. J. Gow D. A. Mccsc, J. J. Fitzpatrick, E. I). Waddington and J. F. Bolzan. 1997. Grain-scale processes, folding and stratigraphic disturbance in the GISP2 ice core. 7. Geophs. Res. 102 C12, 26,819 26,830.

Azuma, X. 1994. A flow law for anisotropic ice and its application to ice sheets. Earth Pianet. Sci. I.ell, 128 3-4, 601-614.

Azuma, V. and K. Goto-Azuma. 1996. An anisotropic flow law for ice-sheet ice and its implications. Ann. Glaciol. 23, 202-208.

Barlow, R. J. 1989. Statistics: a guide to the use of statishal methods in the phowat sciences. New York, John Wiley and Sors.

Bennett, H. F. 1968. An investigation into velocity anisotropy through measurements of ultrasonic-wave velocities in snow and ice cores from Greenland and Antarctica. Ph. D. thesis, Lniversity of Misconsin-Madison.

Bohrcn, C. F. 1983. Golors of snow, frozen waterlalls and icebergs. F. Oph. Su Am., Ser. B. Opt. Phys. 73 (12), 16461652.

Budd, W. F. and T. H. Jacka. 1989. A review of ice rheology for ice sheet modelling. Cold Reg. Sci. Terhno, 16(2), 107 144.

Castclnau, O., P. Duwal, R. Lebensohn and G. R. Canova. 1996. Viscoplastic modeling of texture development in polycrystalline ice with a self-consitent approach: comparison with bound estimates. F. Geophys. Res, 101 B $66,13,851-13,868$. 
Cuffey, K., H. Conway, A. Gades, B. Hallet, R. Sletten and C. Raymond. 1996. Tunneling in the name of science: Meserve Glacier revisited. [Abstract.] EOS, 77(46), Fall Mrcting Supplement, F57.

Dahl-Jensen, D. 1985. Determination of the flow properties at Dye 3, south Greenland, by bore-hole-tilting measurements and perturbation modelling. 7. Glaciol., 31 (108), 92-98.

Dahl-Jensen, D. and X.S. Gundestrup. 1987. Constitutive properties of ice at Dyc 3 , Grecnland. Intermational Association of Hydological Sciences Publication 170 (Symposium at Vancouver 1987 The Phyical Basis of Ke Sheet Modetling), $31-13$

Duval, P. 1981. Creep and fabrics of polycrystalline ice under shear and compression. 7. Glaciol., 27(95; 129-140.

Duval, P. and H. le Gac. 1980 . Does the permanent creep-rate of polycrystalline ice increase with crystal size? 7. Glaciol., 25 $(91$ ), $151-157$.

Duval, P. and H. Ic Gac. 1982. Mechanical behaviour of Antarctic inc. Ann. Glaciol., 3, 9295.

Duval, P., M. F. Ashby and I. Anderman. 1983. Rate-controlling processes in the creep of polverystalline ice. F. Phrs. Chem., 87(21, 4066-4074

Echelmeyer, K. and W. Zhongxiang. 1987. Direcl observation of basal sliding and deformation of basal drift at sub-freezing temperatures. 7 . Glaciol, 33(113), $83 \cdot 98$

Glen,J.W. 1958. The flow law of ice: a discussion of the assumptions made in glacier theory, their experimental foundation and consequences. Internalional Association of Scientific Hydrology Publication 47 (Symposium at Chamonix 1958 - Physics of the Movement of the Ice), 171183

Gundestrup, N. S. and B. I. Hansen. 1984. Bore-hole survey at Dye 3, south Greenland. f. Glaciol., 30 106;, 282288.

Hammer, C. U., H. B. Clausen, W. Dansgaard, $\Lambda$. Neftel, P. Kristinsdottir and E. Johnson. 198.5. Continuous impurity analysis along the Dye 3 deep core. In Langway, C.C.., Jr, H. Oeschger andW. Dansgaard, eds. Greenland ice core: geophysics, geochemistr, and the environment. Washington, DC, American Geophysical Union, 90-94. (Geophysical Monograph 33.)

Herron, S. L., C. C. Langway, Jr and K. A. Brugger. 1985. Ultrasonic velorities and crystalline anisotropy in the ice core from Dye 3, Grecnland. In Langway, C.C., Jr, H. Oeschger and W. Dansgaard, eds. Greenlond ice core: geophysics, geochemistry, and the environment. Washington, DC, American Geophysical Union, 23-31. (Geophysical Monograph 33.)

Hooke, R. L.eB., B. B. Dahlin and M.'T. Kauper. 1972. Crecp of irc containing dispersed fine sand. 7. Glaciol., 11(63),327-336.

Jones, S. J. and J.W. Glen. 1969. The effert of dissolved impurities on the mechanical properties of ice crystals. Philos. Mag., 19(157), 13-24

Kamb, W. B. 1961. The glide direction in ice. $f$. Glaciol., 3(30), 1097-1106.

Means, W. D. and M.W. Jessel. 1986. Accommodation migration of grain boundaries. Tectonophysics, 127,67-86.
Molinary, A., G. Canova and S. Ahzi. 1987. A self consistent approach of the large deformation polycrystal viscoplasticity. Acta Metall, 3512, $2983-2994$

Nakanura, T. and S. J. Jones. 1970. Softening effect of dissolved hydrogen chloride in ice crystals. Scr. Metall, 4/2, 123126

Nakamura, T. and S.J. Jones. 1973. Mechanical properties of impure ice crystals. In Whalley, E., S. J. Jones and L. W. Gold, eds. Physirs and chemistry of ice. Ottawa, Ont., Royal Society of Canada, 365-369.

Paterson, W. S. B. 1991. Why ice-age ice is sometimes "soft". Cold Reg. Sit. Technot., 20(1), 75-98.

Paterson, W. S. B. 1994. 7 he physics of glaciers. Third edition. Oxford, etc., Elsevier.

Percz, J., C. Maï, J. Tatiboüt and R. Vassoille. 1980. 1)ynamical behavior of dislocations in HF-doped ice Ih. F. Glaciol, 25 (91, 133149

Pimienta, P., P. Duval and V.Ya. Lipenkov: 1988. Mechanical behavior of ice along the $2040 \mathrm{~m}$ Vostok rore, Antarctica. Amn. Glaciol., 10, 137-140.

Russell-Head, D. S. and W. F. Budd. 1979. Ice-sheet flow properties derived from bore-hole shear measurements combined with ice-core studies. 7 . Glaciol, 24(90), 117-130)

Sachs, C. 1928. Zur Ableitung einer Fließbedingung. Z. Vereins Disth. Ing., $72(8), 734736$.

Shoji, H. and C. C. Langway, Jr. 1985. Mechanical properties of fresh ice core from Dye 3, Greenland. In Langway; C. C.. Jr, II. Oeschger and W: Dansgaard, eds. Greenland ice core: geophysics, geochemistry, and the emironment. Washington, DC, American Geophysical Union, 39 48. (Geophysical Monograph 33.

Shoji, H. and C. C. Langway, Jr. 1987. Flow velocity profiles and accumulation rates from mechanical tests on ice core samples. International Association of Hydrological Sciences Pubication 170 Symposium at Vancouver 1987 - The Physical Basis of Ice Sheet Modelling). $67-77$.

Shoji, H. and C. C. Langway, Jr. 1988. Flow-law parameters of the 1)ye 3, Greenland, deep ice core. Ann. Glaciol, 10, 146150.

Steinemann, S. 1958. Résultats expérimentaux sur la dynamique de la glace et leurs corrélations avec le mouvement et la pétrographie des glaciers. International Association of Scientific Hydrology Publication 47 (Symposium at Chamonix 1958 - Physics of the Motement of the Ice), 184-198.

Swinzow, G. K. 1962. Investigation of shear zones in the ice sheet margin, Thule area, Greenland. J. Glaciol., 4(32), 215-229.

laylor, K. C. 1982. Sonic logging at 1)ye 3, Grecnland. (M.Sc, thesis, University of Wisconsin, Madison.)

Van der Veen, C. J. and I. M. Whillans. 1990. Flow laws for glacier ice: comparison of numcrical predictions and ficld measurements. 7 . Glaciol., 36 124$), 324339$.

Weertman, J. 1973. Creep of ice. In Whalley, E., S. J. Jones and L. Gold, eds. Physics and chemistry of ice. Ottawa, Ont., Royal Society of Canada, 320--337

MS received 29 August 1997 and accepted in revised form 22 Derember 1998 